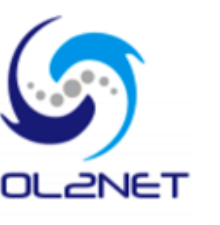

\title{
Purification and biochemical characterization of a novel detergent-stable serine alkaline protease from Bacillus safensis strain RH12
}

\author{
Hatem Rekik ${ }^{1,2}$, Nadia Zaraî Jaouadi ${ }^{1,2}$, Fares Gargouri ${ }^{1}$, Wacim Bejar ${ }^{1}$, Fakher Frikha ${ }^{1}$, \\ Najah Jmal $^{3}$, Samir Bejar ${ }^{1,2}$, Bassem Jaouadi ${ }^{1,2, *}$
}

1 Laboratory of Microbial Biotechnology and Engineering Enzymes (LMBEE), Centre of Biotechnology of Sfax (CBS), University of Sfax, Road of Sidi Mansour Km 6, PO Box 1177, Sfax 3018, Tunisia: rekik.hatem@hotmail.fr, nedia.zarai@yahoo.fr, fares.gargouri90@gmail.com, wacim.bejar@hotmail.fr, frikha_fakher@yahoo.fr, samir.bejar@cbs.rnrt.tn, bassem.jaouadi@yahoo.fr

${ }^{2}$ Biotech ECOZYM Start-up, Business Incubator, Centre of Biotechnology of Sfax (CBS), University of Sfax, Road of Sidi Mansour Km 6, P.O. Box 1177, Sfax 3018, Tunisia rekik.hatem@hotmail.fr, nedia.zarai@yahoo.fr, samir.bejar@cbs.rnrt.tn, bassem.jaouadi@yahoo.fr

${ }^{3}$ STE JMAL (EJM)-Laundry Detergent Industry, Z.I. Avenue August 13, Z.I. Poudriere 1, P.O. Box 407, Boustene, Sfax 3000, Tunisia ejm.direction@ gmail.com

* Authors to whom correspondence should be addressed; E-Mail: bassem.jaouadi@cbs.rnrt.tn

Tel.: +21699535253

Received: / Accepted: / Published:

\begin{abstract}
:
A novel protease (SAPRH) was hyper-produced $(9000 \mathrm{U} / \mathrm{mL})$ from Bacillus safensis $\mathrm{RH} 12$, a newly isolated enzyme from a Tunisian offshore oil field. The enzyme was purified to homogeneity, using salt precipitation, heat-treatment and FPLC anion-exchange chromatography (Fast protein liquid chromatography). SAPRH was a monomer of molecular mass of $\sim 28 \mathrm{kDa}$. The $\mathrm{NH}_{2}$-terminal 23 amino-acid sequence of SAPRH showed high homology with those of Bacillus-proteases. SAPRH displayed optimal activity at $\mathrm{pH} 9$ and $60{ }^{\circ} \mathrm{C}$. It was strongly inhibited by (PMSF, Phenylmethane sulfonyl fluoride) and (DFP, Diisopropylfluorophosphate), indicating that it belongs to the serine-proteases family. One of the most distinctive properties is its catalytic efficiency, which is higher than that of Alcalase $2.5 \mathrm{~L}$, type DX (commercial enzyme) and SAPB from Bacillus pumilus strain CBS. Interestingly, the results of the wash performance analysis demonstrated considerably good de-staining at $40{ }^{\circ} \mathrm{C}$ for 30 min with low supplementation $(500 \mathrm{U} / \mathrm{mL})$. The sapRH gene, which encodes the serine alkaline protease SAPRH, from Bacillus safensis strain RH12, was isolated and its DNA sequence was determined. The highest sequence identity value (97\%) was obtained with SAPB from $B$. pumilus strain CBS, with only 9 amino-acids of difference. The region, encoding SAPRH was
\end{abstract}


heterologously expressed in $E$. coli BL21- AI $^{\text {TM }}$ cells using GATEWAYTM pDEST $^{\text {TM}} 17$ expression-vector.

Keywords: protease; Bacillus safensis; Offshore; oil field; Detergent; Wash performance.

Mol2Net YouTube channel: http://bit.do/mol2net-tube

YouTube link: please, paste here the link to your personal YouTube video, if any.

\section{Introduction}

Enzymes are fascinating the researchers owing to their enormous power of catalysis and eco-friendly nature. Since community demands are largely increasing, a continuous need to evolve enzymes is notably required. In fact, the techniques and computational tools have immensely developed keeping pace with the cutting-edge industries to meet the growing demands. Correspondingly, techniques such as protein engineering helps in the development of quality products by mutating the amino acids in order to make more stable and efficient product (Kumar et al., 2017). Enzymes are used in several environmental-friendly industrial purposes, as they are efficient, selective, and accelerate; they also speed up reactions by

\section{Results and Discussion}

\section{Identification of the microorganism RH12}

the morphological, biochemical, and physiological characteristics revealed that the RH12 isolate appeared in a bacilli form, and it was an aerobic, spore-forming rod, Grampositive, catalase-positive, oxidase-positive, and motile, and colonies are round, undulate, dull white and non-luminescent. The carbohydrate profile of the isolate was further investigated using API $50 \mathrm{CH}$ gallery tests. All the data obtained with regard to the physiological and biochemical properties of the isolate, therefore, strongly confirmed that the RH12 strain belonged to the Bacillus genus. In order to further support the findings related to the identification of strain RH12, the 16S rRNA gene sequence obtained was submitted to GenBank BLAST search analyses. Likewise, the results displayed strong homology with those of several cultivated strains of Bacillus, reaching a maximum sequence identity of $99 \%$. The nearest Bacillus strains identified by the BLAST analysis were the Bacillus safensis strain SAFN-037 (accession no. AY167880) and Bacillus safensis strain FO-036bT (accession no. AF234854). forming transition-state complexes with their substrate, which reduces the activation energy of the reaction (Bharathiraja et al., 2017; Singh et al., 2016). Accordingly, the present study reports on the purification and biochemical characterization of a novel detergent stable protease (SAPRH) from Bacillus safensis strain RH12 isolated from offshore sediment in the Gulf of Gabes (Tunisia). It also provides basic information on the potential use of SAPRH as a prospective candidate for future applications in detergent formulations mainly with Class, a commercial liquid laundry detergent from the local company JMAL (EJM).

\section{SAPRH production and production}

The protease production is composed of $(\mathrm{g} / \mathrm{L})$ : galactose, 10; yeast extract, $4 ; \mathrm{CaCl}_{2}, 2 ; \mathrm{K}_{2} \mathrm{HPO}_{4}$, 0.5 ; and $\mathrm{KH}_{2} \mathrm{PO}_{4}, 0.5$; the addition of trace elements at $2 \%(\mathrm{v} / \mathrm{v})$ at $\mathrm{pH}$ 7.4. The protein elution profile obtained at the final purification step indicated that the protease was eluted at 220-300 mM NaCl. The results of the purification procedure are summarized in Table 1. Enzyme purity was estimated to be 43 -fold higher than that of the crude extract. Under optimum assay conditions, the purified enzyme had a specific activity of $37000 \mathrm{U} / \mathrm{mg}$, with a yield of about $19 \%$.

To analyze the homogeneity and molecular weight of the purified SAPRH, native-PAGE (Polyacrylamide gel electrophoresis) and SDSPAGE (Sodium dodecyl sulfate polyacrylamide gel electrophoresis) were performed. The molecular mass of the purified enzyme was estimated to be approximately $28 \mathrm{kDa}$, as assessed by native-PAGE (data not shown). Further, single band by SDS-PAGE analysis showed the subunit molecular weight of approximately $28 \mathrm{kDa}$, indicating the high purity 
of the enzyme. The SDS-PAGE analysis exhibited single band, indicating that the purified SAPRH enzyme was a monomeric protein consisted of one molecular weight subunit. Zymogram revealed one zone of caseinolytic activity corresponding to purified SAPRH.

\section{Biochemical characterization of SAPRH}

The findings indicated that enzyme activity was strongly inhibited by PMSF and DFP, two wellknown inhibitors of serine proteases. Other inhibitors, such as TPCK (Tosyl phenylalanyl chloromethyl ketone) and TLCK (Tosyl-L-lysylchloromethane hydrochloride), a chymotrypsin alkylating agent, benzamidine, a trypsin competitive reagent, SBTI, and a soybean trypsin inhibitor, were used and observed to have no inhibitory effects on enzyme activity. Moreover, the thiol reagent (DTNB, (5,5-dithio-bis-(2nitrobenzoic acid), NEM, (N-Ethylmaleimide) and iodoacetamide) had almost no influence on enzyme activity.

\section{Influences of additive on protease stability}

When SAPRH was pre-incubated for $1 \mathrm{~h}$ at 40 ${ }^{\circ} \mathrm{C}$ in the presence of several commercially available laboratory non-ionic surfactants, denaturing agents or anionic surfactants and bleach agents, a higher stability in the presence of $15 \%$ Tween 20 , Tween 40 or Triton X-100 and the strong anionic surfactants, particularly SDS and LAS was observed compared to SAPB; and Alcalase $2.5 \mathrm{~L}$, type DX. SAPRH was also highly stable against bleaching agents since it retained 160 and $85 \%$ of its initial activity after treatment with $15 \%$ hydrogen peroxide and $5 \%$ sodium perborate, respectively, vs 109 and $61 \%$ for SAPB and 150 and $83 \%$ for Alcalase $2.5 \mathrm{~L}$, type DX, respectively. This stability is of interest since only a few wild-type proteases have been reported to be oxidant, surfactant and bleach stable. KERAB, keratinase from Streptomyces sp. strain $\mathrm{AB} 1$, was remarkably stable in the presence of 5\% Tween 40, 1.5\% SDS, and 15\% $\mathrm{H}_{2} \mathrm{O}$. The data to compared to Alcalase $2.5 \mathrm{~L}$, type DX and SAPB, SAPRH is extremely stable and compatible with the commercial liquid and solid laundry detergents used at a concentration of $7 \mathrm{mg} / \mathrm{mL}$, retaining $100 \%$ of their initial activity with Class, Ecovax, and Dipex (vs 88, 100 , and $91 \%$ for SAPB and 75,90 , and $90 \%$ for Alcalase $2.5 \mathrm{~L}$, type DX, respectively). The data illustrated in Fig. 1 also indicate that SAPRH exhibited high stability, i.e. N88\% with Nadhif (vs $81 \%$ for SAPB and $80 \%$ for Alcalase $2.5 \mathrm{~L}$, type DX) even after $1 \mathrm{~h}$ incubation at $40{ }^{\circ} \mathrm{C}$. The alkaline proteases SAPRH and SAPB were noted to be less stable in the presence of Ariel (75 and $67 \%$ ) and Skip (83 and 74\%).

\section{Stains removal from cotton fabrics}

Several pieces of stained cotton cloth were incubated at different conditions and used to evaluate the performance of SAPRH and Alcalase $2.5 \mathrm{~L}$, type DX in terms of their ability to remove blood, egg, and chocolate stains. As shown in Fig. 2, a limited washing performance was observed with detergent (Class) only.

The supplementation of SAPRH or commercial protease Alcalase $2.5 \mathrm{~L}$, type DX in detergent seems to improve the cleaning process as evidenced by rapid blood stain removal when compared to detergent alone. In fact, SAPRH facilitated the release of proteinaceous materials in a much easier way than the currently used Alcalase $2.5 \mathrm{~L}$, type DX protease. Furthermore, the combination of SAPRH with the Class liquid detergent resulted in the complete stain removal (Fig. 2).

\section{Molecular cloning and DNA analysis of the sapRH gene encoding SAPRH}

Using the protease gene sequences of Bacillus strains, two primers, called F-RH50 and RRH51, were designed and used to amplify a fragment of about $1.4 \mathrm{~kb}$ that could contain the sapRH gene. This PCR fragment was purified and cloned in a pCR-Blunt cloning vector using an $E$. coli Top10 host strain, thus leading to the recombinant plasmid pHR1.

The recombinant thermostable serine alkaline protease (His6-rSAPRH) from B. safensis strain RH12 was expressed, purified, and characterized in E. coli strain BL21-AITM using the GATEWAYTM Cloning Technology. 
Table 1. Flow sheet for SAPRH purification from Bacillus safensis strain RH12

\begin{tabular}{|c|c|c|c|c|c|}
\hline Purification step & $\begin{array}{l}\text { Total activity } \\
\text { (units) }{ }^{\mathrm{a}, \mathrm{b}} \times 10^{3}\end{array}$ & $\begin{array}{ll}\text { Total } & \text { protein } \\
(\mathrm{mg})^{\mathrm{a}, \mathrm{c}} & \end{array}$ & $\begin{array}{l}\text { Specific activity (U/mg of } \\
\text { protein) }\end{array}$ & $\begin{array}{ll}\text { Activity } & \text { recovery } \\
\text { rate }(\%) & \end{array}$ & $\begin{array}{l}\text { Purification factor } \\
\text { (fold) }\end{array}$ \\
\hline Crude extract & $4,500 \pm 75$ & $5250 \pm 90$ & $857 \pm 135$ & 100 & 1 \\
\hline $\begin{array}{l}\left(\mathrm{NH}_{4}\right)_{2} \mathrm{SO}_{4} \text { Fractionation } \\
65 \%) \text {-dialysed }\end{array}$ & $3,735 \pm 49$ & $1,233 \pm 21$ & $3,029 \pm 243$ & 83 & 3.53 \\
\hline Heat treatment $\left(30 \mathrm{~min}\right.$ at $\left.65^{\circ} \mathrm{C}\right)$ & $1,800 \pm 21$ & $135 \pm 10$ & $13,334 \pm 451$ & 40 & 15.55 \\
\hline FPLC (UNO Q-6) & $851 \pm 10$ & $23 \pm 2$ & $37,000 \pm 898$ & 19 & 43 \\
\hline
\end{tabular}

Figure 1. Washing performance analysis test of SAPRH.

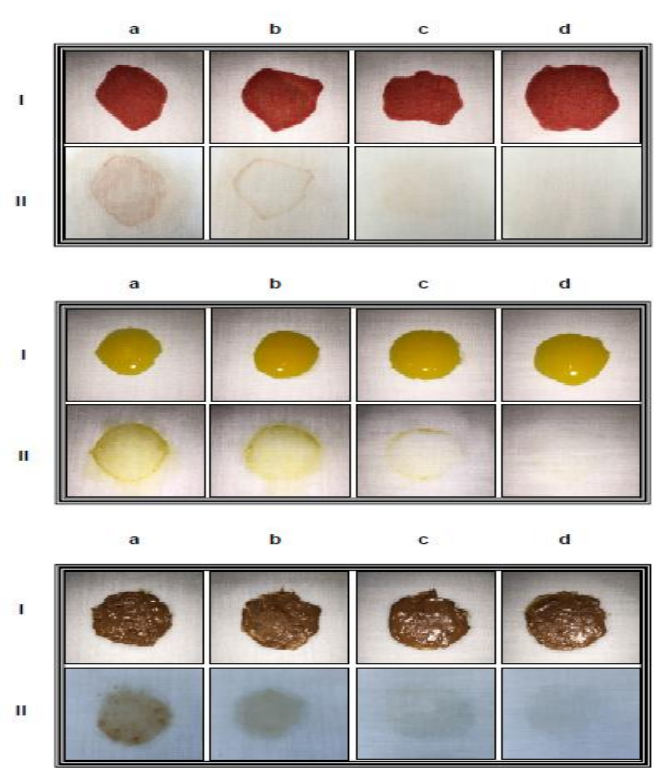

\section{Materials and Methods}

\section{Experimental}

\section{Isolation and protease-producing}

Isolations were made at $37{ }^{\circ} \mathrm{C}$ from marine sediment in the deep Mediterranean Sea. They were freshly collected from a petroleum reservoir in "Hasdrubal", an offshore oil and gas site belonging to the BritishGas Tunisia Ltd. company. The Hasdrubal oil and gas field is located $100 \mathrm{~km}$ offshore Tunisia in the Gulf of Gabes.

\section{Classical and molecular identification RH12}

The morphological, cultural, physiological, and biochemical characteristics of the bacterium were investigated as well described by a previous detailed study (Jaouadi et al., 2008).

\section{Assay of proteolytic activity:}

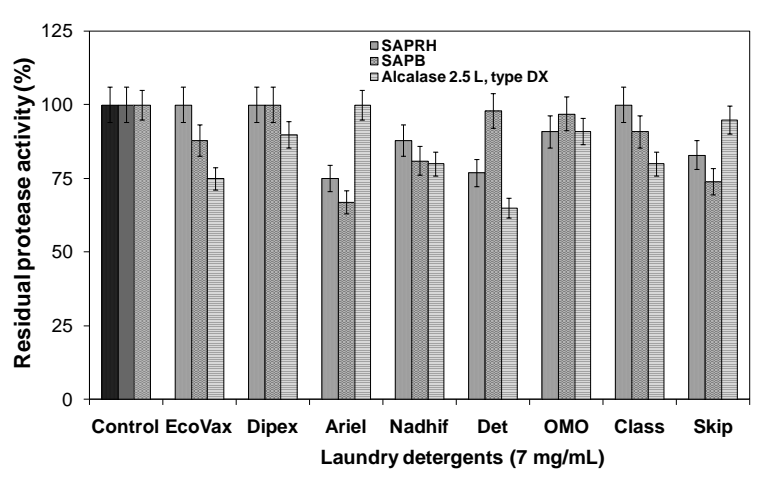

Protease activity assay was carried (Kembhavi et al., 1993), using Hammerstein casein (Merck, Darmstadt, Germany) as a substrate. The proteolytic activity present in the laundry detergent solution was evaluated as described elswhere (Touioui et al., 2015) using N,Ndimethylated casein (DMC) as a substrate.

\section{Protease purification:}

Five hundred milliliters of a 22-h culture of Bacillus safensis strain RH12 was centrifuged for $30 \mathrm{~min}$ at $9000 \mathrm{~g}$ to remove microbial cells. The supernatant containing extracellular protease was used as the crude enzyme preparation and submitted to the following purification steps. It was initially saturated up to $45-65 \%$ and dialyzed overnight against the repeated changes of the same buffer. The clear supernatant was incubated for $30 \mathrm{~min}$ at $65^{\circ} \mathrm{C}$. The supernatant was loaded and applied to an FPLC system, using a $12 \mathrm{~mm} \times$ 
$53 \mathrm{~mm}$ UNO Q-6 chromatography column equilibrated with buffer $B$. The elution of proteins was carried out with a flow rate of 1 $\mathrm{mL} / \mathrm{min}$ by using a linear $\mathrm{NaCl}$ gradient ranging from 0 to $500 \mathrm{mM}$ in the same buffer and detected using a UV/VIS Spectrophotometric detector at $280 \mathrm{~nm}$.

\section{Gene cloning and expression of the protease}

Two oligonucleotides were synthesized, based on the high degree of sequence homology published for the protease gene of Bacillus strains and utilized for the isolation and determination of the sapRH encoding gene sequence (Benkiar et al., 2013; Jaouadi et al., 2008).
These findings advise on the usefulness of SAPRH in future industrial applications as a cleaning bioadditive in detergent formulations. this is the first report pertaining to the cloning sapRH gene from Bacillus safensis, encoding a serine alkaline protease (SAPRH), which is endowed with a number of properties that are highly valued for the detergent industry. Further studies, some of which are currently underway in our laboratories, are needed to hyperproduce the SAPRH enzyme in Pichia pastoris system and to explore its structure-function relationships using site-directed mutagenesis approach.

\title{
4. Conclusions
}

\section{Acknowledgments}

The authors would like to think to Mrs. N. Masmoudi, Mrs. N. Kchaou, and Mr. K. Walha (Analysis Unit-CBS) for their technical assistance. We would also like to express their gratitude to Pr. H. Belghith and Dr. W. Saibi (CBS) for their constructive suggestions and discussions. Special thanks are also due to Pr. W. Hariz from the English Department at the Sfax Faculty of Science, University of Sfax (Sfax, Tunisia) for language polishing services and constructively proofreading.

\section{Author Contributions}

Conceived and designed the experiments: BJ.

Performed the experiments: HR, NZJ.

Analyzed the data: NZJ, HR, SB, BJ.

Contributed reagents/materials/analysis tools: NZJ, HR.

Wrote the text of the paper: HR, NZJ.

Critical revision of manuscript: HR, NZJ, SB, BJ.

Proofreading and polishing the language of the present paper: $\mathrm{WH}, \mathrm{BJ}$.

\section{Conflicts of Interest}

The authors declare that they have no conflict of interest.

\author{
Abbreviations \\ FPLC: Fast protein liquid chromatography \\ PMSF: Phenylmethane sulfonyl fluoride \\ DFP: Diisopropylfluorophosphate \\ PAGE: Polyacrylamide gel electrophoresis \\ SDS-PAGE: Sodium dodecyl sulfate polyacrylamide gel electrophoresis \\ TPCK: Tosyl phenylalanyl chloromethyl ketone \\ TLCK: Tosyl-L-lysyl-chloromethane hydrochloride \\ DTNB: 5,5-dithio-bis-(2-nitrobenzoic acid \\ NEM: N-Ethylmaleimide \\ KERAB: keratinase from Streptomyces sp. strain AB1 \\ SAPB: Serine Alkaline Protease from Bacillus pumilus CBS
}


Mol2Net-04, 2018, BIOCHEMPHYS-01 (pages 1- x, type of paper, doi: $x x x-x x x x$

http://sciforum.net/conference/mol2net-4 6

\section{References and Notes}

Benkiar, A., Zaraî Jaouadi, N., Badis, A., Rebzani, F., Soraya, B.T., Rekik, H., Naili, B., Ferradji, F.Z., Bejar, S., Jaouadi, B. 2013. Biochemical and molecular characterization of a thermo-and detergent-stable alkaline serine keratinolytic protease from Bacillus circulans strain DZ100 for detergent formulations and feather-biodegradation process. International Biodeterioration \& Biodegradation, 83, 129-138.

Bharathiraja, S., Suriya, J., Krishnan, M., Manivasagan, P., Kim, S.-K. 2017. Production of enzymes from agricultural wastes and their potential industrial applications. in: Advances in food and nutrition research, Vol. 80, Elsevier, pp. 125-148.

Jaouadi, B., Ellouz-Chaabouni, S., Rhimi, M., Bejar, S. 2008. Biochemical and molecular characterization of a detergent-stable serine alkaline protease from Bacillus pumilus CBS with high catalytic efficiency. Biochimie, 90(9), 1291-1305.

Kembhavi, A.A., Buttle, D.J., Knight, C.G., Barrett, A.J. 1993. The two cysteine endopeptidases of legume seeds: purification and characterization by use of specific fluorometric assays. Archives of biochemistry and biophysics, 303(2), 208-213.

Kumar, V., Baweja, M., Liu, H., Shukla, P. 2017. Microbial enzyme engineering: applications and perspectives. in: Recent advances in Applied Microbiology, Springer, pp. 259-273.

Singh, R., Kumar, M., Mittal, A., Mehta, P.K. 2016. Microbial enzymes: industrial progress in 21st century. 3 Biotech, $\mathbf{6}(2), 174$.

Touioui-Boulkour,B., Zaraî Jaouadi, N., Boudjella, H., Ferradji, F.Z., Belhoul, M., Rekik, H., Badis, A., Bejar, S., Jaouadi, B. 2015. Purification and biochemical characterization of two detergentstable serine alkaline proteases from Streptomyces sp. strain AH4. World Journal of Microbiology and Biotechnology, 31(7), 1079-1092. 